\title{
Impact of Invasive Bees on Plant-Pollinator Interactions and Reproductive Success of Plant Species in Mixed Nothofagus antarctica Forests
}

\author{
Jl Agüeroo ${ }^{1,2}$ (1), N Pérez-Méndez ${ }^{2,3}$, JP Torretta ${ }^{1,2}$, LA Garibaldi ${ }^{4,5}$ \\ ${ }^{1}$ Universidad de Buenos Aires, Facultad de Agronomía, Cátedra de Botánica General, Buenos Aires, Argentina \\ ${ }^{2}$ Consejo Nacional de Investigaciones Científicas y Técnicas, Instituto de Investigaciones en Recursos Naturales, Agroecología y Desarrollo \\ Rural, Buenos Aires, Argentina \\ ${ }^{3}$ IRTA, Estació Experimental de l'Ebre, Amposta, Spain \\ ${ }^{4}$ Instituto de Investigaciones en Recursos Naturales, Agroecología y Desarrollo Rural (IRNAD), Sede Andina, Univ. Nacional de Río Negro \\ (UNRN), Río Negro, Argentina \\ ${ }^{5}$ Consejo Nacional de Investigaciones Científicas y Técnicas, Instituto de Investigaciones en Recursos Naturales, Agroecología y Desarrollo \\ Rural, Río Negro, Argentina
}

\section{Keywords}

Honey bees, Bumblebees, Exotic pollinators, Pollination

\section{Correspondence}

JI Agüero, Universidad de Buenos Aires, Facultad de Agronomía, Cátedra de Botánica General, Buenos Aires, Argentina; jaguero@agro.uba.ar

Edited by Márcia M Maués - Embrapa

Received 18 September 2019 and accepted 20 May 2020

Published online: 30 July 2020

(C) Sociedade Entomológica do Brasil 2020

\begin{abstract}
Invasive social bees can alter plant-pollinator interactions with detrimental effects on both partners. However, most studies have focused on one invasive bee species, while the interactions among two or more species remain poorly understood. Also, many study sites had a history of invasive bees, being hard to find sites with historical low abundances. In Patagonia, Bombus ruderatus (F.) invasion begun in 1993 and B. terrestris (L.) in 2006. Though honey bees (Apis mellifera L.) introduction started in 1859, their density is still low in some parts. By experimentally increasing honey bee densities, we evaluated the effect of honey bees and bumblebees floral visitation on native pollinator floral visitation, pollen deposition, and reproductive success of three plant species in mixed Nothofagus antarctica forests of northern Patagonia: Oxalis valdiviensis, Mutisia spinosa and Cirsium vulgare. Our results show that exotic bees became the main floral visitors. No negative association was found between invasive bee and native pollinator visitation rates, but there was evidence of potential competition between honey bees and bumblebees. Floral neighborhood diversity played an important role in pollinator behavior. Conspecific pollen deposition was high for all species, while deposition of heterospecific pollen was very high in $M$. spinosa and $C$. vulgare. Not as expected, honey bees visitation rate had a negative effect on heterospecific pollen deposition in $C$. vulgare. For $O$. valdiviensis, exotic visitation rates increased conspecific pollen deposition, which was positively related to reproductive success. Although exotic bees became main floral visitors, their contribution to reproductive success was only clear for one species.
\end{abstract}

\section{Introduction}

Invasive bee species can alter native plant-pollinator interactions, with effects on both partners. As they can reach high numbers, exotic bees can compete with native pollinators for floral resources and nesting sites (Goulson 2003, Mallinger et al 2017, Agüero et al 2018). As a consequence, native pollinator fitness and population dynamics can be 
compromised (Thomson 2004, Paini \& Roberts 2005). Moreover, the displacement of native pollinators might affect plant species partners thus the entire communities of both plants and pollinators are subject to modifications (Aizen et al 2008). Yet most studies have focused on the impact of one single invasive species on pollination patterns while the interaction between two or more invasive species remains unexplored.

Invasive bees can affect pollination outcomes in both direct and indirect ways. Directly, they can trigger pervasive negative effects on pollen flow if they behave as pollen thieves or if they promote selfing (Mendes do Carmo et al 2004, Traveset \& Richardson 2006, Dohzono et al 2008). Because some invasive bees (e.g. honey bees and bumblebees) are generalist species (i.e., forage on a wide range of plant species) they are associated with an increase in heterospecific pollen deposition (Traveset \& Richardson 2006, Marrero et al 2016). Indirectly, they can affect pollination by modifying the behavior of more efficient pollinators or by reducing pollen availability (Dohzono et al 2008). These modifications to pollen quantity/quality balance are expected to negatively affect plant reproductive success (Dohzono et al 2008, Magrach et al 2017, Valido et al 2019). It is thus necessary to assess the impact of invaders on plantpollinator interaction patterns and plant reproductive success to better understand and forecast the response of plant communities to the introduction of novel invasive pollinator species.

Worldwide, honey bees (Apis mellifera L.) and bumblebees (Bombus spp.) are recognized as some of the most important invasive pollinator species (Stout \& Morales 2009). Honey bees have been introduced for honey production and crop pollination all over the world except Antarctica (Moritz et al 2005, Abrol 2012). The spread of some bumblebee species is more recent and is related to crop pollination (Stout \& Morales 2009). In the last decades, two species of bumblebees began to invade Argentinean Patagonia, after being introduced into Chile. It is thought that Bombus ruderatus (F.) invasion begun in 1993 and Bombus terrestris (L.) in 2006 (Roig-Alsina \& Aizen 1996, Torretta et al 2006, Morales et al 2013). Apis mellifera introduction started in 1859 (Pérez Rosales 1859, Sanguinetti \& Singer 2014).

Although numerous studies show that these social bees can disrupt plant-pollinator interactions with negative effects on both partners (Morales \& Aizen 2006, Aizen et al 2008, de M Santos et al 2012, Magrach et al 2017, Valido et al 2019), no one has assessed the combined effect of the two groups of pollinators (i.e. honey bees and bumblebees) on plant-pollinator interaction and reproductive success of plant biota in Argentinean Patagonia.

Mixed Nothofagus antarctica forests of northern Patagonia represent one of the main forestal community of the Argentinean Patagonia. This community is one of the most diverse ecosystems in the region and is characterized by many plant species that rely on animal-mediated pollination (Aizen and Ezcurra 1998, Speziale et al 2010). The relative recent invasion of $B$. terrestris and $B$. ruderatus to mixed $N$. antarctica forests of northern Patagonia and the low density of honey bees in some sites provide a good scenario for experimental sites that are relatively new to the presence of invasive bees. This also allows us to study their potential novel effects when they coexist. Therefore, by experimentally increasing honey bee density in a locality where invasive bumblebees ( $B$. ruderatus and $B$. terrestris) are common flower visitors, we studied the effect of both groups of pollinators on plant-pollinator interaction in three different plant species of the mixed $N$. antarctica forests. To do this, we evaluated four different aspects: i) behavioral response of pollinators to the floral neighborhood, ii) the relationship between native and invasive pollinator visitation rates (i.e. potential competition), iii) changes in pollen deposition patterns and iv) changes in reproductive success of the three plant species. First, we expect that an increase in floral neighborhood diversity will lead to an increase in the visitation rate of invasive bees on focal plant individuals. Second, that an increase in invasive bee visits will negatively relate to native pollinators visits. Third, we expect that the increase in exotic pollinator visitation rates will increase both conspecific and heterospecific pollen deposition. Finally, we hypothesize that this increase in pollen deposition will not necessarily lead to an increase in reproductive success because of a decrease in pollen quality.

\section{Materials and Methods}

\section{Study site}

The study was performed at the proximity of the locality El

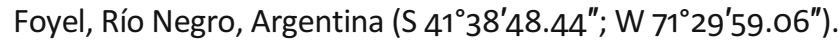
This ecosystem represents a forest/steppe ecotone, dominated by $N$. antarctica (Forst.) Oerst., accompanied with other woody species such as Lomatia hirsuta (Lam.) Diels ex J.F. Macbr., Schinus patagonicus (Phil.) I. M. Johnst. ex Cabrera and Diostea juncea (Gillies ex Hook.) Miers (Gyenge et al 2009). The climate is characterized by a mean annual temperature of $9.7^{\circ} \mathrm{C}$ (mean range $3.1^{\circ} \mathrm{C}-16.7^{\circ} \mathrm{C}$ ) and an average annual rainfall of $920 \mathrm{~mm}$, with a probability of frost throughout the year (Reque et al 2007).

\section{Studied species}

Oxalis valdiviensis Barnéoud (Oxalidaceae) is a perennial herb, 5-25 cm tall (Zuloaga and Belgrano 2017) with cymose inflorescences bearing 9-31 flowers. Flowers are yellow and 
Fig 1 Flowers and inflorescences of the three studied species (a) Oxalis valdiviensis, (b) Mutisia spinosa and (c) Cirsium vulgare and one of the invasive bumblebee species: Bombus terrestris
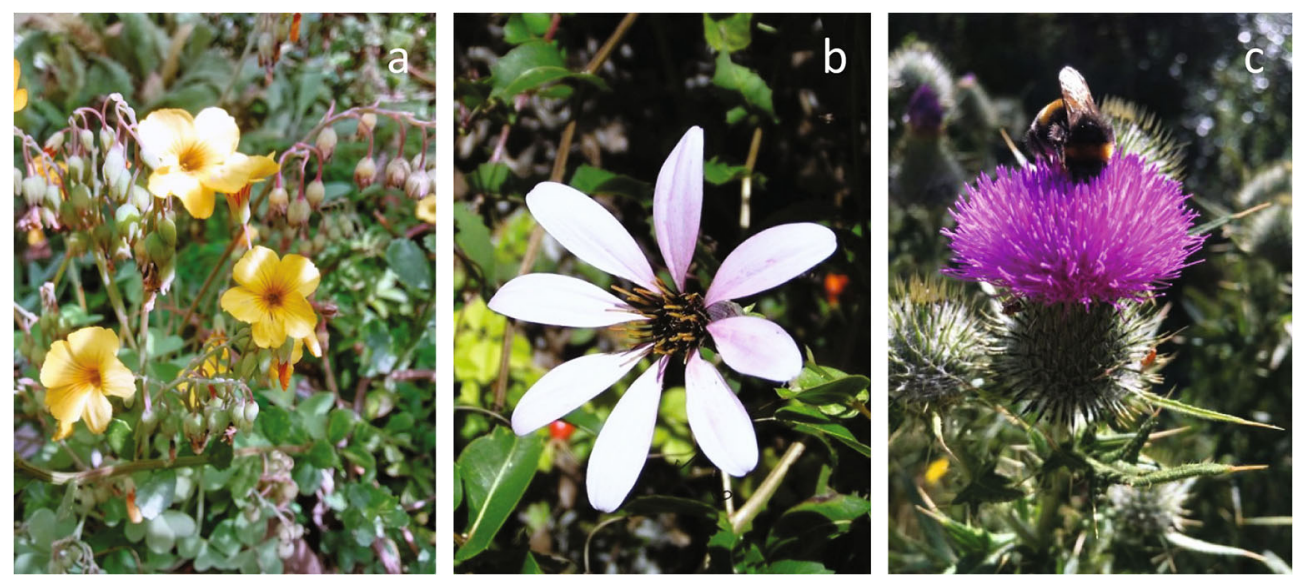

up to $25 \mathrm{~mm}$ in diameter (Fig $1 \mathrm{~A}$ ) and the fruit is a capsule. It is an endemic species to Argentinean and Chilean Andes.

Mutisia spinosa Ruiz \& Pav. (Asteraceae) is a semi-woody climber plant (Zuloaga \& Belgrano 2017). Flowers are disposed of in solitary heterogamy capitula. Ray flowers (8-10) with ligulate light pink corollas (Fig 1B). The tube is ca. $15 \mathrm{~mm}$ long and the ligule is elliptic, ca. $30 \times 8 \mathrm{~mm}$. Numerous disk flowers with tubular yellow corollas, tube ca. $20 \mathrm{~mm}$ long. The fruit is a glabrous achene $15 \mathrm{~mm}$ long. It is an endemic species to southern Argentina and Chile.

Cirsium vulgare (Savi) Ten. (Asteraceae) is an annual or biennial herb that growths $0.5-2 \mathrm{~m}$ tall (Zuloaga and Belgrano 2017). The inflorescence consists of big capitula (mean = $15.7 \mathrm{~mm}$, Fenner et al 2002) with purple bisexual flowers (Fig 1C). The fruit is an achene 3.5-4.8 mm long, slightly asymmetrical. Although native to Europe, West, Central and South Asia, North Africa and the Azores Islands; it is naturalized in most part of Argentina.

All three plant species whose blooming period overlap and have entomophilous pollination (Coulin personal observations, Madjidian et al 2008, Morales \& Aizen 2002). Particularly, previous studies in this region demonstrated that $M$. spinosa main pollinator used to be the native giant bumblebee Bombus dahlbomii (Guer.) whose population is declining currently (Madjidian et al 2008).

\section{Experimental design}

In the study site, exotic bumblebees $(B$. terrestris and $B$. ruderatus) density (0.0097 individuals $/ \mathrm{m}^{2}$ ) is higer than honey bee density $\left(0.000065\right.$ individuals $/ \mathrm{m}^{2}$ ) (Coulin et al 2019). In order to increase honey bee abundance in relation to exotic bumblebees, we brought 10 beehives to the site on January 12, 2017, and taken care of during the experiment in the site.
During the flowering season, we selected 16 individuals for each plant species. Plant individuals were separated more than $2 \mathrm{~m}$ from each other and marked with a code number. All individuals were located no more than $1 \mathrm{~km}$ from the hives so that they were included in the normal honey bee foraging range, which is 2-3 km (Abrol 2012). In each analyzed individuals, we marked closed buds to identify which flowers were only exposed to an increase in honey bee abundance for pollen deposition and reproductive success analysis.

\section{Visitation rates and floral neighborhood characterization}

We measured visitation rates on all plant individuals from January 26, 2017 to February 20, 2017. To estimate visitation rates on each focal plant, we registered the total number of floral visitors during a specific period of time on a known (previously counted) number of flowers. It is worth to note that only those floral visitors that touched the reproductive parts of the flower were taken into account as a legitimate visit. Census started in the morning (ca. 10:00 h) up to afternoon (ca. 16:30 h). To avoid variation due to differences in the time of the day, we changed the order of individual census in every repetition. Mean total visit time for each plant individual is ca. $54 \mathrm{~min}$.

We also characterized the flowering neighborhood in a circular plot ( $1 \mathrm{~m}$ of radius) around each studied individual. We registered in each plot the number of flowering individuals for all plant species and the number of open flowers.

\section{Pollen deposition}

We collected at least 10-20 flowers for each individual in post-anthesis from the previously marked buds and store them in $70 \%$ alcohol. In the lab, we randomly selected three flowers from each individual from each species. First, we separated the stigmatic area of each flower and macerated for $24 \mathrm{~h}$ in $\mathrm{NaOH}$ : water 1:10 (w:v). Then, we added a drop of melted glycerol-gelatine containing safranin on a slide, place one stigma and squashed it carefully with a coverslip 
(Zarlavsky 2014). The safranin is used to stain the pollen grains and allowed better identification. Later, using a microscope, we counted the number of conspecific and heterospecific pollen grains on the stigma. For the identification, we analyzed the pollen morphology of each studied species by applying the same method to pollen grains directed collected from the anthers. For further information, we also consulted the corresponding bibliography.

\section{Reproductive success}

In each individual, we also marked at least three buds or preanthesis capitula that were exposed to an increase in honey bee abundance. When the fruits of each plant individual were matured, we collected them (capsules of Oxalis were removed pre-dehiscence). Each capitulum of both Asteraceae species was collected and stored in paper bags, while 0 . valdiviensis fruits were stored in $70 \%$ alcohol for later analysis.

For each $O$. valdiviensis fruit, we counted the number of well-formed seeds (viable) in each locule. Seeds that were disintegrated or too small with a different color were considered as atrophied. We also counted the number of ovules per locule which we observed varied between two and three among individuals. Therefore, we estimated the correct value for each individual by counting the number of ovules per locule in three flowers per individual. Differences in ovule production have also been observed in other Oxalis species: O. alpina (Weller 1981), O. magnifica (Guth \& Weller 1986), $O$. corniculata (Abid 2010). For Asteraceae species, we distinguished for each capitulum the number of well-formed achenes (healthy) from those that were hollow or shrunken. Achenes that are hollow or shrunken may indicate that they are infertile (Michaux 1989).

In the case of $O$. valdiviensis, we could not analyze 5 of the 16 individuals for reproductive success. For M. spinosa, for three individuals we could only analyze two capitulum, for two one capitulum and for one individual we did not have data. Those individuals for which we did not have data were not included in the model. Finally, for 6 individuals of C.vulgare we analyzed two capitulum and for one, only one capitulum.

\section{Data analysis}

For describing floral neighborhood diversity we calculated Simpson's diversity (1-D) (Simpson 1949, Lande 1996). We grouped the floral visitors into three different categories: honey bees (A. mellifera), exotic bumblebees (B. terrestris and $B$. ruderatus) and native pollinators. Native pollinators include all other species visiting the flowers.

We calculated the visitation rate (measured as individuals/min*flower or capitulum) per pollinator category and both the number of conspecific and heterospecific pollen grains on stigma for each plant individual for each plant species. For $C$. vulgare and M. spinosa, we calculated the reproductive success as the number of healthy achenes divided by the total number of achenes. For $O$. valdiviensis, we calculated the reproductive success as the number of viable seeds divided by the total number of ovules.

We used structural equation modeling (SEM) to fit a path analysis to test our multiple hypotheses. SEM allows testing hypothesis related to causal relationships even in complex models (Mitchell 1992). We used the "SEM" function in the R package Lavaan (Rosseel 2012) for fitting all of our structural equations. Path analysis assumes normality so we transformed the variables to improve the normality of distribution: square root transformation for honey bees, bumblebees and native pollinators visitation rate, conspecific pollen grains and heterospecific pollen grains values and arcsin square root transformation for Simpson diversity index and for reproductive success values. We evaluated models to fit with a chi-squared test and Comparative Fit Index (CFI). We incorporated $\mathrm{CFI}$ because is less sensitive to sample size (Ainur et al 2017).

We constructed an initial theoretical model for the three species (Appendix Fig 4). Our model proposed causal links for our six variables of interest: Simpson's diversity (1-D), honey bees visitation rate, native pollinators visitation rate, bumblebees (B. terrestris and $B$. ruderatus) visitation rate, conspecific pollen grains (mean number of conspecific pollen grains deposited on stigma), heterospecific pollen grains (mean number of heterospecific pollen grains deposited on stigma) and reproductive success (number of viable seeds/total number of ovules for $O$. valdiviensis or healthy achenes/total number of achenes for M. spinosa and C. vulgare) (Appendix Fig 4).

Initially, the Chi-square value $>0.05$ and $\mathrm{CFI}<<0.95$, which indicates that goodness of fit of the models is not good (Hu and Bentler 1999). In order to improve the models, we included paths suggested by the analysis of the modification indices (MIs) (Mitchell 1992, Rosseel 2012). We only included parameters that have a biological interest. After this, the goodness of fit of each model improved considerably (chi-square value $>0.05$ and $\mathrm{CFI} \geq 0.95$ ). This is why the final structural equations differ from our initial theoretical model for the Asteraceae species. Additionally, we also analyzed the correlation among the transformed variables by using Pearson's $r$ ('record' function of the 'Hmisc' R-package) (Appendix Table 2).

\section{Results}

For all studied species, data fitted properly our proposed model after incorporating influential relationships based on modifications indices: $O$. valdiviensis: $P$ value (Chi-square) $=$ 0.319; $\mathrm{CFI}=0.93 ; M$. spinosa: $P$ value (Chi-square) $=0.466$; 
$\mathrm{CFI}=1.00 ;$. vulgare: $P$ value (Chi-square) $=0.361 ; \mathrm{CFI}>0.97$. In general, there is a good correlation between path analysis results and Pearson correlation values, although the level of significance may differ for some relations between variables (Appendix Table 2).

\section{Pollinator Categories Visitation Rate and Floral Neighborhood Diversity}

Mean visitation rates were higher for honey bees and native pollinators in $O$. valdiviensis and for bumblebees follow by honey bees in both $M$. spinosa and $C$. vulgare (Fig 2). Path analysis shows that floral neighborhood had more frequently a significate positive effect on at least a pollinator category visitation rate for all plant species. In this sense, plant neighborhood diversity had a significant positive effect on native pollinators in $O$. valdiviensis, a significant positive effect on honey bees in $M$. spinosa and on honey bees in $C$. vulgare (Fig 3). Contrary, it had a negative effect on bumblebees visitation rate on $C$. vulgare.

\section{Potential Competition with Native Pollinators}

We found no significant negative effect of exotic pollinators, honey bees and bumblebees, on native visitation rate in any plant species (Fig 3). Instead, we found a significant positive relation between exotic bumblebees and native pollinators visitation rate in $M$. spinosa (Fig 3). We also found a significant positive relation between honey bee and bumblebees visitation rate in $C$. vulgare. We did not observe that any encounter between invasive bees and native floral visitors disrupted the foraging behavior of the last ones.

Fig 2 Barplot showing visitation rates of each defined pollinator categories (bumblebees, honey bees and native pollinators) for the three studied plant species (Oxalis valdiviensis, Mutisia spinosa, and Cirsium vulgare). Error lines indicate standard errors (SE). For each plant species, different letters indicate values that differ significantly (first ANOVA, then Tukey's test: $P$ value $<0.05$ )

\section{Pollen Deposition}

Mean conspecific pollen grains deposited on stigma was one order of magnitude higher for $O$. valdiviensis (339.2 \pm 55.12 ) than $M$. spinosa $(92.11 \pm 11.15)$ and $C$. vulgare $(30.96 \pm 4.56)$ (Table 1). Contrarily, mean heterospecific pollen grains deposited on stigma were highest for $C$. vulgare (35.25 \pm 7.20$)$, followed by $M$. spinosa $(26.38 \pm 4.54)$ and $O$. valdiviensis $(11.53 \pm 4.18)$ (Table 1). For $O$. valdiviensis, we found a significant effect of honey bees and native pollinators visitation rate on mean conspecific pollen deposition and a marginal significant relation between bumblebees and conspecific pollen grains (Fig 3). Moreover, native pollinators visitation rate had an also positive effect on heterospecific pollen deposition in O. valdiviensis (Fig 3). Bumblebees visitation rate had a marginally significant positive effect on heterospecific pollen grains in $C$. vulgare. While, contrarily to our hypothesis, we found that honey bees visitation rate had a significant negative effect on heterospecific pollen deposition in C. vulgare (Fig 3). We found no effect between pollinator categories and pollen deposition in M. spinosa (Fig 3).

\section{Reproductive Success}

Mean reproductive success was extremely high for $C$. vulgare (0.92 \pm 0.03 ), while $O$. valdiviensis and $M$. spinosa had similar values (0.63 \pm 0.05 and $0.64 \pm 0.03$, respectively) (Table 1). Based on our path analysis, we found a marginal significant relation between conspecific pollen deposition and reproductive success of $O$. valdiviensis (Fig 3). As expected we found a negative but marginal significant relation between heterospecific pollen deposition and reproductive success also for $O$. valdiviensis (Fig 3).

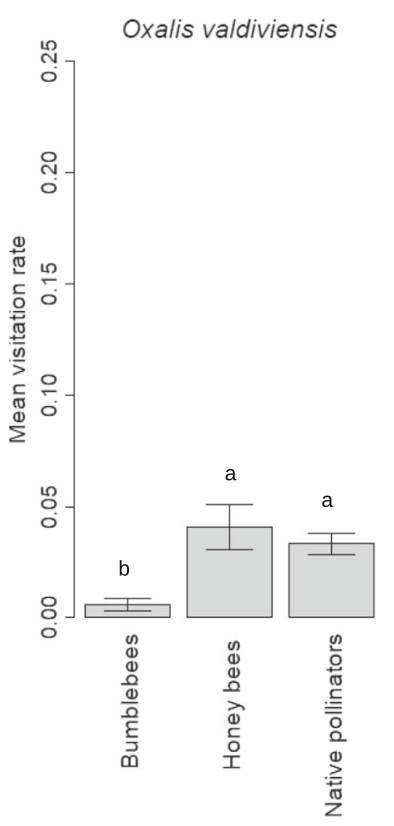

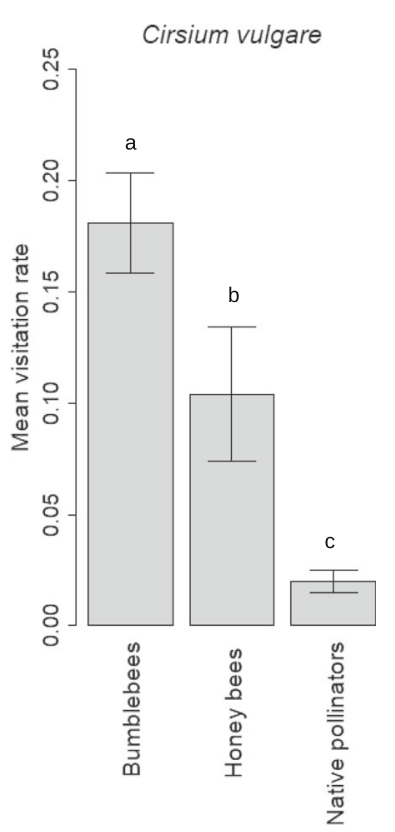



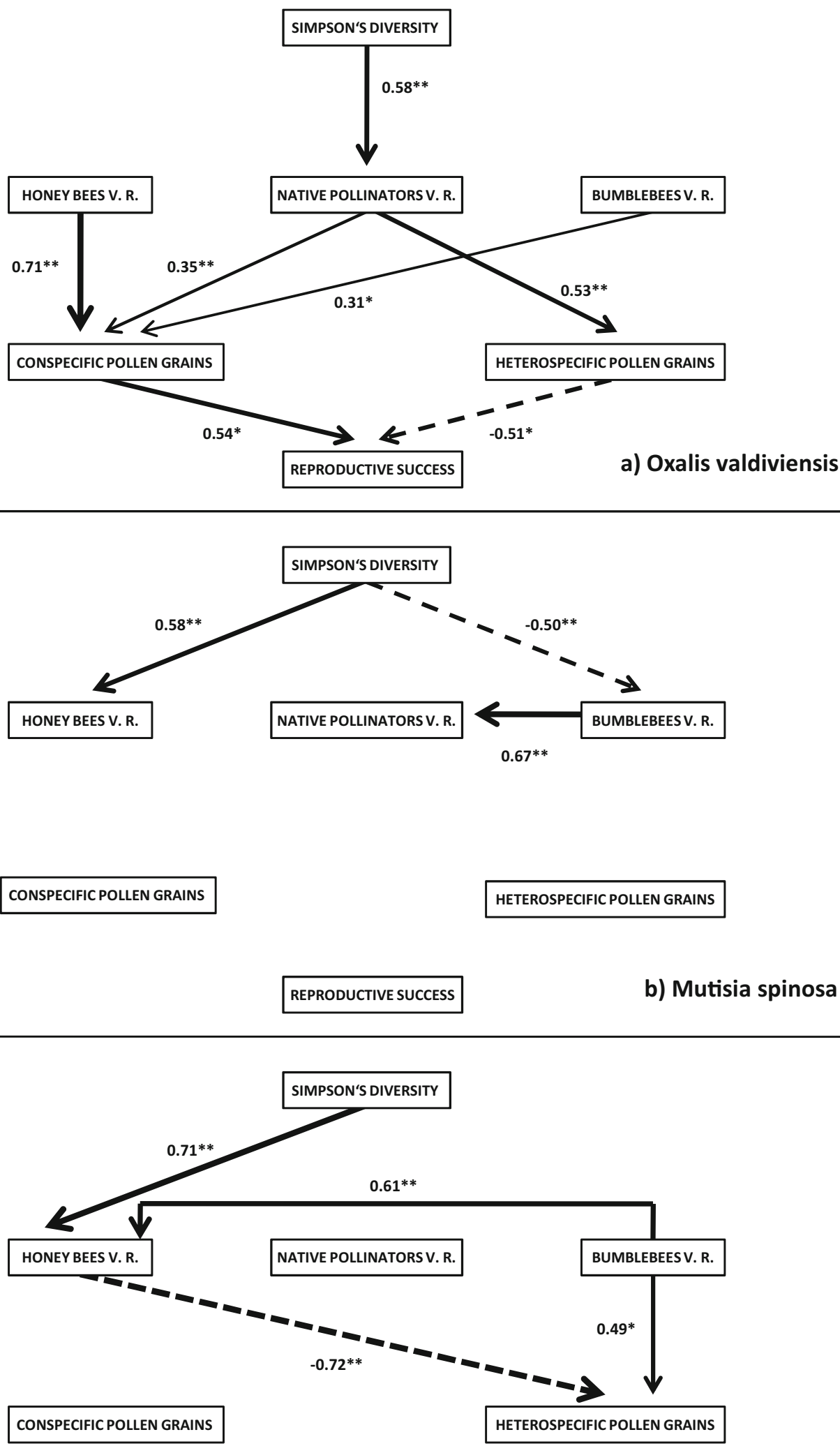

REPRODUCTIVE SUCCESS

c) Cirsium vulgare 
Fig 3 Path analysis showing the most important causal relationships between the variables of interest for each of the studied plant species (a) Oxalis valdiviensis, (b) Mutisia spinosa and (c) Cirsium vulgare.Variables: Simpson's diversity (1-D), honey bees v. r. (honey bees visitation rate), native pollinators $v$. $r$. (mean native pollinators visitation rate), bumblebees v. r. (mean Bombus terrestris and $B$. ruderatus visitation rate), conspecific pollen grains, heterospecific pollen grains and reproductive success (number of viable seeds/ total number of ovules for $O$. valdiviensis or healthy achenes/ total number of achenes for $M$. spinos $a$ and $C$. vulgare). The models show the magnitude of the standardized coefficients of each path (arrows width) and their significance $\left({ }^{* *}: P\right.$ value $\left.<0.05\right)$ or marginal significance $\left({ }^{*}: P\right.$ value $0.05-$ 0.1). Full lines represent positive effects and dotted lines negative effects.

\section{Discussion}

Our study shows that invasive bees became main floral visitors for the three studied plant species, with the diversity of floral neighborhood playing a considerable role in their behavior. Honey bees and native visitors were the main pollinators of $O$. valdiviensis contributing to conspecific pollen deposition, which marginally related to an increase in reproductive success. Cirsium vulgare, an exotic species mainly pollinated by exotic bees, had a high reproductive success. Mutisia spinosa, a native species whose local main pollinator is in decline and for which we did not record any visit (e.i., B. dahlbomii), had surprisingly an intermediate reproductive success. Invasive bumblebees may be contributing, at least partially, to the pollination of this species.

Flower neighborhood diversity was an important component shaping the foraging behavior of pollinators (i.e. visitation rate), especially for honey bees (Fig 3). We found a predominantly positive effect of flower diversity on pollinator visitation rates, a pattern that has been highlighted in several studies (Sih \& Baltus 1987, Molina-Montenegro et al 2008, Muñoz \& Cavieres 2008). Mechanisms such as the combined attraction by convergent floral syndromes or plants providing complementary resources can increase generalist pollinator visits (Ghazoul 2006). Solitary bees with small foraging ranges can also tend to nest in areas with high floral diversity and resource availability (Bruckman and Campbell 2014). However, competition rather than facilitation can also occur between plants, the result depending on factors such as the composition and density of floral neighborhoods (Ghazoul 2006, Morales \& Traveset 2009, Waters et al 2014). In our study, C. vulgare co-flowering around $M$. spinosa may be more attractive for bumblebees. This exotic thistle was the most common species present in $M$. spinosa floral neighborhood and bumblebees have innate preferences for violet and blue colors (Giurfa et al 1995).

Contrary to our hypothesis, we did not found a negative relation between invasive bees and native pollinators visitation rate that could suggest a potential competition or displacement. Instead, we found a positive relation in $M$. spinosa. A positive relation between invasive bees and native pollinators has already been observed (Mallinger et al 2017). However, the absence of potential competition cannot be ruled out. The positive relationship can be by the preference of both pollinators for the same plant individual or by competition between them. The second hypothesis is based on the idea that if the competition is reducing the resource availability per flower, animals could be visiting more flowers for collecting the quantity they require (Maloof \& Inouye 2000). For O. valdiviensis and C. vulgare, the absence of a negative interaction may be because the actual density of exotic bees is not sufficient to reduce resource availability.

The hypothesis related to resource reduction could also explain the positive relation between honey bee and bumblebee visitation rates in $C$. vulgare. These generalist bees have a high preference for this exotic plant species (Morales \& Aizen 2006). If visits by honey bees and bumblebees reduce the amount of nectar and/or pollen per capitulum, both can increase the number of visits to obtain the quantity they require. The fact that we observed honey bees and bumblebees fighting for foraging in capitulum also supports this. Interspecific scent marks could also explain this behavior: bumblebees and honey bees tend to avoid or depart quickly from flowers that were previously visited by an individual of the different species (Stout \& Goulson 2001).

Table 1 The mean and standard error (SE) of the number of conspecific and heterospecific pollen grains deposited on stigma and the reproductive success for the three plant species (Oxalis valdiviensis, Mutisia spinosa and Cirsium vulgare). For each column, different letters indicate values that differ significantly (first ANOVA, then Tukey's test: $P$ value $<0.05$ )

\begin{tabular}{llll}
\hline Plant species & Conspecific pollen grains & Heterospecific pollen grains & Reproductive success \\
\hline Oxalis valdiviensis & $339.21( \pm 55.12) \mathrm{a}$ & $11.53( \pm 4.18) \mathrm{b}$ & $0.63( \pm 0.05) \mathrm{b}$ \\
Mutisia spinosa & $92.11( \pm 11.15) \mathrm{b}$ & $26.38( \pm 4.54) \mathrm{ab}$ & $0.64( \pm 0.03) \mathrm{b}$ \\
Cirsium vulgare & $30.96( \pm 4.56) \mathrm{b}$ & $35.25( \pm 7.20) \mathrm{a}$ & $0.92( \pm 0.03) \mathrm{a}$ \\
\hline
\end{tabular}


As expected, we found that honey bee and bumblebee visitation rates related positively to conspecific pollen deposition but only in $O$. valdiviensis. Honey bees can be efficient pollinators outside their native range because they are generalists, and their pollination effectiveness can be similar to that of native pollinators (Hung et al 2018). Even if they are less efficient, their high abundance may compensate it (Agüero et al 2018). In the studied region, exotic bumblebees have demonstrated to be efficient pollinators, for example, of some orchids species (Sanguinetti \& Singer 2014). Even though we did not found the same pattern for $M$. spinosa and $C$. vulgare, the mean number of conspecific pollen grains was very high as Asteraceae flowers only have one ovule per flower. This shows that these species could not be experiencing pollen limitation, at least at the quantity level (Aizen \& Harder 2007). This also suggests that the lack of a clear increase in conspecific pollen deposition with an increase in pollinator visitation rates could be due to pollen saturation (Aizen \& Harder 2007).

Contrarily to our hypothesis, we did not find a relevant positive effect of invasive bees visitation rates on heterospecific pollen deposition. Only bumblebees visitation rate had a marginally positive effect in $C$. vulgare. Interestingly, honey bees visitation rate had a negative relation. Although honey bees and bumblebees are both generalist species, they are both also characterized by their flower constancy (Goulson 2010, Grüter \& Ratnieks 2011). Flower constancy is relatively higher for honey bees (Goulson 2010) and this characteristic may reduce the chances of deposition of heterospecific pollen on stigmas. However, it is important to note that $C$. vulgare, which was mainly visited by both categories of invasive bees, had the highest proportion of heterospecific pollen deposition. Native pollinators visitation rate related positively to heterospecific pollen deposition in $O$. valdiviensis, probably because different species with different behavior and morphology were grouped in this category.

An increase in exotic bee visitation rates may be beneficial for the reproductive success of $O$. valdiviensis. All the pollinator categories contributed to conspecific pollen deposition and there was a significant effect of conspecific and heterospecific pollen deposition on reproductive success. Despite the high conspecific pollen deposition, pollen quality limitation can be important cause $O$. valdiviensis presents tristyly as a crossbreeding system: three different morphotypes differ in the length of the style and the length of the two whorls of the stamen (Fyfe 1950). Effective pollination occurs when pollen comes from individuals with different morphotypes. Honey bees tend to forage several flowers of the same inflorescence or individual before moving to another, which could reduce the quality of the pollen (i.e., increasing geitonogamy) (Paton 1997). Another interesting aspect is that heterospecific pollen grains, although mean grains were high, were related to reproductive success. Heterospecific pollen can reduce reproductive output by different mechanisms such as allelopathic inhibition of conspecific pollen (Morales \& Traveset 2008). Those detrimental effects can even be independent of conspecific pollen load size (Arceo-Gómez \& Ashman 2011).

We observed no effect of conspecific pollen deposition on the reproductive success of $M$. spinosa. Their primary pollinator is $B$. dahlbomii, whose population is declining, and it has been suggested that invasive bumblebees may not be able to replace it (Madjidian et al 2008). In our study mean reproductive success was $64 \%$, even though exotic bumblebees were the main pollinators. The number of deposited conspecific pollen grains on stigma was very high, suggesting that other factors are limiting its reproductive success such as pollen quality or nutrient limitation (De Jong and Klinkhamer 1989; Niesenbaum 1993; Morales \& Traveset 2008).

Cirsium vulgare, an exotic species mainly visited by both exotic bees, had an extremely high reproductive success showing that this plant species does not suffer from a limitation in pollen quantity or quality. Positive interaction between invasive bees and exotic plant species has already been demonstrated (Goulson 2003, Morales et al 2009, Traveset \& Richardson 2014). Even though we did not found a positive relation between exotic bees and conspecific pollen deposition, this data may suggest that both honey bees and bumblebees are contributing positively to the reproductive success of C. vulgare.

Based on our data, we can conclude that invasive bees do not compromise the reproductive success of the studied plant species. It is important to bear in mind that our work is based on variation in the visitation rates at the individual level during one growing season and native pollinators were analyzed as "one group". However, it is an important contribution to understanding the processes associated with the potential impact of invasive bees in the area and serves as a guide for future research.

Acknowledgments We are grateful to C. Coulin and A. Antokoletz, G. J. Huerta, C.A. John and D. H. Bascur for their vital contribution to the project. We also thank G. Zarlavsky and B. G. Galati for their collaboration in pollen analysis. We are grateful to Márcia Maués, Carmen Pires and Cláudia Inês Silva for inviting us to participate in this Special Volume of Neotropical Entomology. The manuscript benefited from critical reading of two anonymous reviewers. This research was funded by Agencia Nacional de Promoción Científica y Tecnológica (PICT 2013-1079 and PICT 2016-0305). JIA, NPM, JPT and LAG are affiliated with CONICET.

Author Contribution Statement JIA and LAG contributed to the design and implementation of the research. JIA, NPM, JPT and LAG contributed to the analysis of the results and to the writing of the manuscript. LAG supervised the project since its original idea. All authors approved the final version of the manuscript. 


\section{Appendix}

Fig 4 Theoretical path diagram incorporating all the hypothetical causal relationships between the variables of interest for the three studied plant species. Variables: Simpson's diversity (1-D), honey bees v. r. (honey bees visitation rate), native pollinators $v$. $r$. (mean native pollinators visitation rate), bumblebees v. $r$. (mean Bombus terrestris and B. ruderatus visitation rate), conspecific pollen grains, heterospecific pollen grains and reproductive success (number of viable seeds/total number of ovules for $O$. valdiviensis or healthy/ total number of achenes for $M$. spinosa and C. vulgare). Full lines represent positive effects and dotted lines negative effects

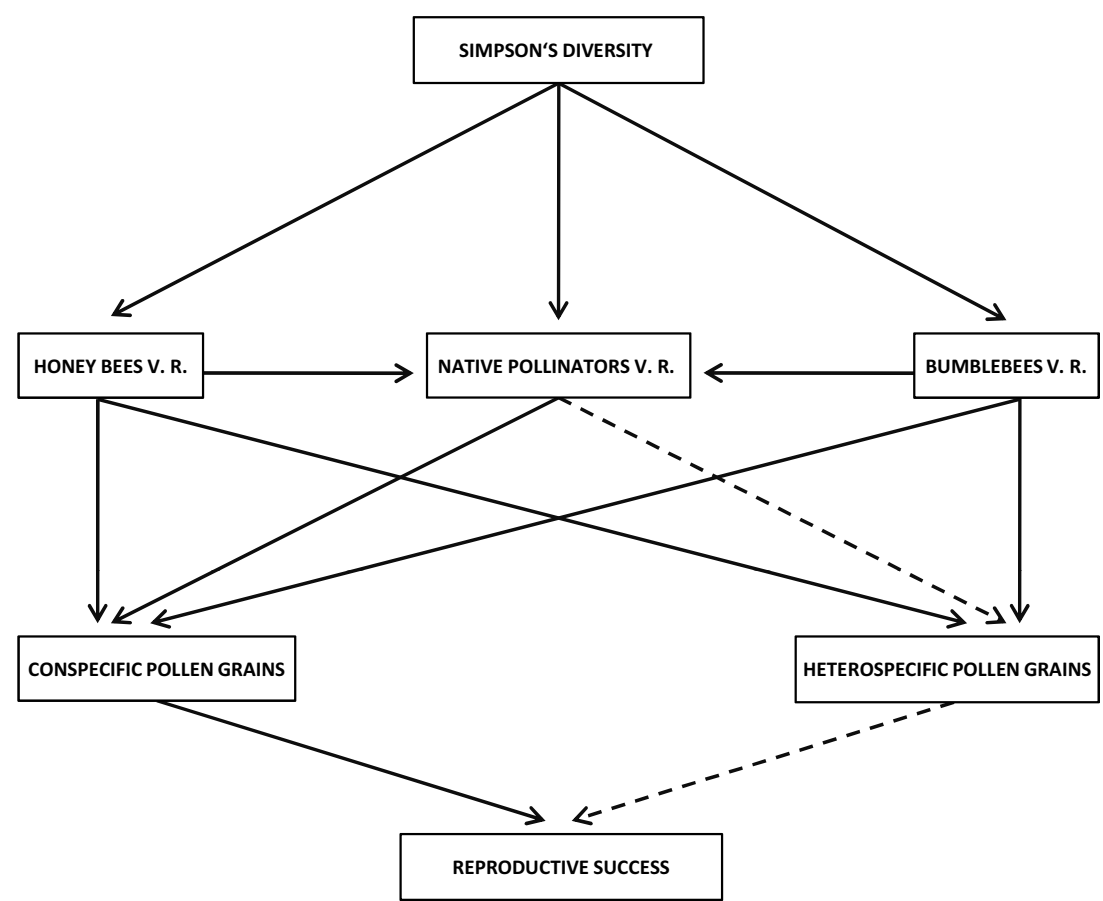

Table 2 Pearson correlation coefficients for all transformed variables of interest for each of the three plant species (a) Oxalis valdiviensis, (b) Mutisia spinosa and (c) Cirsium vulgare. Asterisks indicate significant differences $\left({ }^{* *}: P\right.$ value $\left.<0.05\right)$ or marginal significant differences $(*$ : $P$ value $0.05-0.1)$

$\begin{array}{llllll}\text { Simpson's diversity } & \begin{array}{l}\text { Honey bees } \\ \text { visitation rate }\end{array} & \begin{array}{l}\text { Native pollinators } \\ \text { visitation rate }\end{array} & \begin{array}{l}\text { Bumblebees } \\ \text { visitation rate }\end{array} & \begin{array}{l}\text { Conspecific } \\ \text { pollen grains }\end{array} & \begin{array}{l}\text { Heterospecific } \\ \text { pollen grains }\end{array}\end{array}$

\section{(a) Oxalis valdiviensis}

Honey bees visitation rate

Native pollinators visitation rate

Bumblebees visitation rate

Conspecific pollen grains

Heterospecific pollen grains

Reproductive success

\section{(b) Mutisia spinosa}

Honey bees visitation rate

Native pollinators visitation rate

Bumblebees visitation rate

Conspecific pollen grains

Heterospecific pollen grains

Reproductive success

\section{(c) Cirsium vulgare}

Honey bees visitation rate

Native pollinators visitation rate

Bumblebees visitation rate

Conspecific pollen grains

Heterospecific pollen grains

Reproductive success
0.01

$0.57^{*}$

$-0.05$

0.14

$0.70^{* *}$

$-0.30$

$0.58^{* *}$

$-0.05$

$-0.50 *$

0.36

0.13

0.01

$0.65^{* *}$

0.33

$-0.09$

0.06

$-0.68 * *$

$-0.45^{*}$

-0.11
-0.15
$0.66^{* *}$
0.27
-0.07

$-0.25$

$-0.40$

0.02

$-0.15$

0.13

0.31

$0.55^{* *}$

0.27

$-0.44^{*}$

$-0.30$
$0.55^{* *}$

$-0.16$

$-0.06$

0.22

$-0.04$

$-0.01$

$-0.21$

$-0.05$
$-0.27$

$-0.08$

$0.46 *$

0.04

$-0.29$

$-0.39$ 


\section{References}

Abid R (2010) Floral morphs and mode of pollination in Oxalis corniculata L. from Pakistan. Pak J Bot 42(6):4027-4033

Abrol DP (2012) Pollination biology: biodiversity conservation and agricultural production. Springer, New York

Agüero JI, Rollin O, Torretta JP, Aizen MA, Requier F, Garibaldi LA (2018) Impactos de la abeja melífera sobre plantas y abejas silvestres en hábitats naturales. Revista Ecosistemas 27(2):60-69

Ainur AK, Sayang MD, Jannoo Z, Yap BW (2017) Sample size and nonnormality effects on goodness of fit measures in structural equation models. Pertanika J Sci Technol 25(2)

Aizen MA, Ezcurra C (1998) High incidence of plant-animal mutualisms in the woody flora of the temperate forest of southern South America: biogeographical origin and present ecological significance. Doctoral dissertation, Asociación Argentina de Ecología

Aizen MA, Harder LD (2007) Expanding the limits of the pollen-limitation concept: effects of pollen quantity and quality. Ecology 88(2):271-281

Aizen MA, Morales CL, Morales JM (2008) Invasive mutualists erode native pollination webs. PLoS Biol 6(2):e31

Arceo-Gómez G, Ashman TL (2011) Heterospecific pollen deposition: does diversity alter the consequences? New Phytol 192(3):738-746

Bruckman D, Campbell DR (2014) Floral neighborhood influences pollinator assemblages and effective pollination in a native plant. Oecologia 176(2):465-476

Coulin C, Aizen MA, Garibaldi LC (2019) Contrasting responses of plants and pollinators to woodland disturbance. Austral Ecol 44(6):10401051

De Jong TJ, Klinkhamer PG (1989) Limiting factors for seed production in Cynoglossum officinale. Oecologia 80(2):167-172

Dohzono I, Kunitake YK, Yokoyama J, Goka K (2008) Alien bumble bee affects native plant reproduction through interactions with native bumble bees. Ecology 89(11):3082-3092

Fenner M, Cresswell JE, Hurley RA, Baldwin T (2002) Relationship between capitulum size and pre-dispersal seed predation by insect larvae in common Asteraceae. Oecologia 130(1):72-77

Fyfe VC (1950) The genetics of tristyly in Oxalis valdiviensis. Heredity (Edinb) 4(3):365-371

Ghazoul J (2006) Floral diversity and the facilitation of pollination. J Ecol 94(2):295-304

Giurfa M, Nunez J, Chittka L, Menzel R (1995) Colour preferences of flower-naive honeybees. J Comp Physiol A 177(3):247-259

Goulson D (2003) Effects of introduced bees on native ecosystems. Annu Rev Ecol Evol Syst 34:1-26

Goulson D (2010) Choice of flower species. In: Goulson D (ed) Bumblebees: behaviour, ecology, and conservation. Oxford University Press, Oxford, pp 113-129

Grüter C, Ratnieks FL (2011) Flower constancy in insect pollinators: adaptive foraging behaviour or cognitive limitation? Commun Integr Biol 4(6):633-636

Guth CJ, Weller SG (1986) Pollination, fertilization and ovule abortion in Oxalis magnifica. Am J Bot 73(2):246-253

Gyenge J, Fernández ME, Sarasola M, de Urquiza M, Schlichter T (2009) Ecuaciones para la estimación de biomasa aérea y volumen de fuste de algunas especies leñosas nativas en el valle del río Foyel, NO de la Patagonia argentina. Bosque (Valdivia) 30(2):95-101

Hu LT, Bentler PM (1999) Cutoff criteria for fit indexes in covariance structure analysis: conventional criteria versus new alternatives. Struct Equ Model Multidiscip J 6(1):1-55

Hung KL, Kingston JM, Albrecht M, Holway DA, Kohn JR (2018) The worldwide importance of honey bees as pollinators in natural habitats. Proc R Soc Lond B Biol Sci 285(1870):20172140

Lande R (1996) Statistics and partitioning of species diversity, and similarity among multiple communities. Oikos 76:5-13
Madjidian JA, Morales CL, Smith HG (2008) Displacement of a native by an alien bumblebee: lower pollinator efficiency overcome by overwhelmingly higher visitation frequency. Oecologia 156(4):835-845

Magrach A, González-Varo JP, Boiffier M, Vilà M, Bartomeus I (2017) Honeybee spillover reshuffles pollinator diets and affects plant reproductive success. Nat Ecol Evol 1(9):129

Mallinger RE, Gaines-Day HR, Gratton C (2017) Do managed bees have negative effects on wild bees?: a systematic review of the literature. PLoS One 12(12):e0189268

Maloof JE, Inouye DW (2000) Are nectar robbers cheaters or mutualists? Ecology 81(10):2651-2661

Marrero HJ, Medan D, Zarlavsky GE, Torretta JP (2016) Agricultural land management negatively affects pollination service in Pampeanagroecosystems. Agric Ecosyst Environ 218:28-32

Mendes do Carmo R, Franceschinelli EV, Silveira FA (2004) Introduced honeybees (Apis mellifera) reduce pollination success without affecting the floral resource taken by native pollinators. Biotropica 36:371376

Michaux B (1989) Reproductive and vegetative biology of Cirsium vulgare (Savi) ten. (Compositae: Cynareae). New Zeal J Bot 27(3): 401-414

Mitchell RJ (1992) Testing evolutionary and ecological hypotheses using path analysis and structural equation modelling. Funct Ecol 6:123-129

Molina-Montenegro MA, Badano El, Cavieres LA (2008) Positive interactions among plant species for pollinator service: assessing the "magnet species" concept with invasive species. Oikos 117(12):18331839

Morales CL, Aizen MA (2002) Does invasion of exotic plants promote invasion of exotic flower visitors? A case study from the temperate forests of the southern Andes. Biol Invasions 4(1-2):87-100

Morales CL, Aizen MA (2006) Invasive mutualisms and the structure of plant-pollinator interactions in the temperate forests of north-West Patagonia, Argentina. J Ecol 94(1):171-180

Morales CL, Arbetman MP, Cameron SA, Aizen MA (2013) Rapid ecological replacement of a native bumble bee by invasive species. Front Ecol Environ 11(10):529-534

Morales CL, Traveset A (2009) A meta-analysis of impacts of alien vs. native plants on pollinator visitation and reproductive success of coflowering native plants. Ecol Lett 12(7):716-728

Morales CL, Traveset A (2008) Interspecific pollen transfer: magnitude, prevalence and consequences for plant fitness. CRC Crit Rev Plant Sci 27(4):221-238

Morales C, Traveset A, Ramírez N (2009) Especies invasoras y mutualismos planta-animal. In: Medel R, Aizen MA, Zamora R (eds) Ecología y evolución de interacciones planta-animal. Editorial Universitaria, Santiago de Chile, pp 61-76

Moritz RFA, Härtel S, Neumann P (2005) Global invasions of the western honeybee (Apis mellifera) and the consequences for biodiversity. Ecoscience 12:289-301

Muñoz AA, Cavieres LA (2008) The presence of a showy invasive plant disrupts pollinator service and reproductive output in native alpine species only at high densities. J Ecol 96(3):459-467

Niesenbaum RA (1993) Light or pollen-seasonal limitations on female reproductive success in the understory shrub Lindera benzoin. J Ecol 81:315-323

Paini DR, Roberts JD (2005) Commercial honey bees (Apis mellifera) reduce the fecundity of an Australian native bee (Hylaeus alcyoneus). Biol Conserv 123(1):103-112

Paton D (1997) Honey bees Apis mellifera and the disruption of plantpollinator systems in Australia. Vic Nat 114:23-29

Pérez Rosales V (1859) Ensayo sobre Chile. Librería del Ferrocarril, Santiago de Chile

Reque JA, Sarasola M, Gyenge J, Fernández ME (2007) Caracterización silvícola de ñirantales del norte de la Patagonia para la gestión forestal sostenible. Bosque (Valdivia) 28(1):33-45 
Roig-Alsina A, Aizen MA (1996) Bombus ruderatus Fabricius, un nuevo Bombus para la Argentina (Hymenoptera: Apidae). Physis 5:49-50

Rosseel Y (2012) Lavaan: an R package for structural equation modeling and more. Version 0.5-12 (BETA). J Stat Softw 48(2):1-36

Sanguinetti A, Singer RB (2014) Invasive bees promote high reproductive success in Andean orchids. Biol Conserv 175:10-20

de M Santos GM, Aguiar CML, Genini J, Martins CF, Zanella FCV, Mello MAR (2012) Invasive Africanized honey bees change the structure of native pollination networks in Brazil. Biol Invasions 14(11):2369-2378

Sih A, Baltus MS (1987) Patch size, pollinator behavior, and pollinator limitation in catnip. Ecology 68(6):1679-1690

Simpson EH (1949) Measurement of diversity. Nature 163(4148):688

Speziale KL, Ruggiero A, Ezcurra C (2010) Plant species richnessenvironment relationships across the Subantarctic-Patagonian transition zone. J Biogeogr 37(3):449-464

Stout JC, Goulson D (2001) The use of conspecific and interspecific scent marks by foraging bumblebees and honey bees. Anim Behav 62(1): 183-189

Stout JC, Morales CL (2009) Ecological impacts of invasive alien species on bees. Apidologie 40(3):388-409

Thomson D (2004) Competitive interactions between the invasive European honey bee and native bumble bees. Ecology 85(2): 458-470
Torretta JP, Medan D, Abrahamovich AH (2006) First record of the invasive bumblebee Bombus terrestris (L) (Hymenoptera, Apidae) in Argentina. T Am Entomol Soc 132:285-289

Traveset A, Richardson DM (2006) Biological invasions as disruptors of plant reproductive mutualisms. Trends Ecol Evol 21:208-216

Traveset A, Richardson DM (2014) Mutualistic interactions and Biologicallnvasions. Annu Rev Ecol Evol Syst 45:89-113

Valido A, Rodríguez-Rodríguez MC, Jordano P (2019) Honey bees disrupt the structure and functionality of plant-pollinator networks. Sci Rep 9(1):471

Waters SM, Fisher SE, Hille Ris Lambers J (2014) Neighborhoodcontingent indirect interactions between native and exotic plants: multiple shared pollinators mediate reproductive success during invasions. Oikos 123(4):433-440

Weller SG (1981) Fecundity in populations of Oxalis alpina in southeastern Arizona. Evolution 35(1):197-200

Zarlavsky GE (2014) Histología vegetal: técnicas simples y complejas. Gráfica Arte, Buenos Aires, pp 127-128

Zuloaga FO, Belgrano MJ (2017) Flora Argentina: Flora Vascular de La República Argentina. http://wwwfloraargentinaeduar/ Accessed 26 July 2019

Publisher's Note Springer Nature remains neutral with regard to jurisdictional claims in published maps and institutional affiliations. 